\title{
Cardiothoracic
}

Transplantation

\section{Bridge to lung transplantation with the novel pumpless interventional lung assist device NovaLung}

Stefan Fischer, MD, MSc, ${ }^{a}$ Andre R. Simon, MD, ${ }^{a}$ Tobias Welte, MD, ${ }^{\mathrm{b}}$ Marius M. Hoeper, MD, ${ }^{\mathrm{b}}$ Anna Meyer, MD, ${ }^{\mathrm{a}}$ Rene Tessmann, MD, ${ }^{a}$ Bernhard Gohrbandt, MD, ${ }^{a}$ Jens Gottlieb, MD, ${ }^{b}$ Axel Haverich, MD, and Martin Strueber, MD ${ }^{a}$

From the Hannover Thoracic Transplant Program, Division of Thoracic and Cardiovascular Surgery, ${ }^{\mathrm{a}}$ and the Department of Respiratory Medicine, Hannover Medical School, ' Hannover, Germany.

The results of this study were presented as a featured abstract during a plenary session at the 25th anniversary meeting and scientific sessions of the International Society for Heart and Lung Transplantation (ISHLT), April 6-9, 2005, Philadelphia, Pa.

The authors have no financial interest in any products presented in this article.

Received for publication June 27, 2005; revisions accepted Sept 22, 2005; accepted for publication Oct 10, 2005

Address for reprints: Martin Strueber, MD, Director, Hannover Thoracic Transplant and Cardiac Assist Program, Division of Thoracic and Cardiovascular Surgery, Hannover Medical School, Carl-Neuberg-Strasse 1, 30625 Hannover, Germany (E-mail: strueber@thg. mh-hannover.de).

J Thorac Cardiovasc Surg 2006;131:719-23 0022-5223/\$32.00

Copyright (C) 2006 by The American Association for Thoracic Surgery

doi:10.1016/j.jtcvs.2005.10.050
Background: Worsening of lung failure in patients awaiting a lung transplantation might lead to ventilation-refractory hypercapnia and respiratory acidosis. Most transplant centers consider pretransplantation extracorporeal membrane oxygenation as a contraindication for lung transplantation because of the poor outcome. We have, for the first time, applied the novel pumpless interventional lung assist NovaLung for bridge to lung transplantation in patients with severe ventilationrefractory hypercapnia. We report on our initial experience.

Methods: Between March 2003 and March 2005, 176 lung transplantations were performed, of which $60 \%$ were high-urgency lung transplantations. Twelve of the high-urgency recipients had severe ventilation-refractory hypercapnia and respiratory acidosis. These patients were connected to the novel pumpless interventional lung assist NovaLung for bridge to lung transplantation.

Results: The length of interventional lung assist NovaLung support was $15 \pm 8$ days (4-32 days). $\mathrm{PaO}_{2}, \mathrm{pH}$, and $\mathrm{PaCO}_{2}$ levels in arterial blood prior to interventional lung assist NovaLung implantation were $71 \pm 27 \mathrm{~mm} \mathrm{Hg}, 7.121 \pm 0.1$, and $128 \pm 42$ $\mathrm{mm} \mathrm{Hg}$, respectively. Six hours after interventional lung assist NovaLung implantation, $\mathrm{PaO}_{2}, \mathrm{pH}$, and $\mathrm{PaCO}_{2}$ levels had changed to $83 \pm 17 \mathrm{~mm} \mathrm{Hg}(\mathrm{ns}), 7.344 \pm$ $0.1(P<.05)$, and $52 \pm 5 \mathrm{~mm} \mathrm{Hg}(P<.05)$, respectively. Four patients died of multiorgan failure, 2 patients before and 2 after lung transplantation. Thus, 10 out of 12 patients were successfully bridged to lung transplantation, and 8 are still alive (1-year survival, $80 \%$ ).

Conclusions: This report suggests that interventional lung assist NovaLung implantation is an effective bridge to lung transplantation strategy in patients with ventilation-refractory hypercapnia.

$\mathrm{L}$ ung transplantation (LTx) has become a standard treatment modality for patients with end-stage lung failure, and the worldwide number of procedures annually performed is continuously expanding. ${ }^{1}$ However, the number of patients listed for LTx is also increasing and reaches far beyond the amount of available donor organs. As a consequence, the waiting list mortality is still relevant and, dependent on the underlying disease, might reach $20 \%$ during the first year and up to $40 \%$ after 2 years of listing. ${ }^{2}$ These data clearly indicate that the current waiting times are too long for a relevant number of patients awaiting an LTx. 


\section{Abbreviations and Acronyms \\ $\mathrm{AVCO}_{2} \mathrm{R}=$ arteriovenous $\mathrm{CO}_{2}$ removal \\ $\mathrm{ECMO}=$ extracorporeal membrane oxygenation \\ HU = high urgency \\ iLA = interventional lung assist NovaLung \\ LTx = lung transplantation}

In the EuroTransplant environment, patients who are listed for LTx might be listed for high-urgency (HU) LTx if they fulfill defined criteria of progressing end-stage lung failure. According to the guidelines, these patients have to be hospitalized in the transplant center and often require noninvasive or even invasive ventilatory support. Evidence exists that mechanical ventilation before LTx is a significant risk factor for mortality after $\mathrm{LTx}^{3}$ and certainly needs to be avoided. It carries a high risk of infection, muscle fatigue, ventilation-associated lung injury, and, ultimately, remote organ dysfunction, as previously shown by the Toronto group. ${ }^{4}$ Currently, patients have to wait up to several months for an HU LTx in the EuroTransplant region. As a consequence, approximately $25 \%$ of the HU patients at The Hannover Thoracic Transplant Program require mechanical ventilation before LTx. ${ }^{5}$ Some of these patients, however, might have further life-threatening ventilation-refractory hypercapnia and respiratory acidosis, despite maximal ventilatory support. The only treatment option for these patients is extracorporeal gas exchange. Until now, extracorporeal membrane oxygenation (ECMO) has been the only technical option, but it can be applied for a very limited period of time only and has side effects, such as hemolysis $(>80 \%)$, infection (20\%-25\%), renal insufficiency (30\%-40\%), and bleeding complications (50\%-60\%). Moreover, the outcome of LTx after pre-LTx ECMO implantation is poor, with a perioperative mortality of up to $60 \% .^{6}$

The interventional lung assist NovaLung (iLA; NovaLung $\mathrm{GmbH}$, Hechingen, Germany) is a low-resistance lung assist device designed for pulsatile blood flow with tight diffusion membranes and a protein matrix coating. ${ }^{7}$ It is driven by the cardiac output and therefore does not require extracorporeal pump assistance. In the clinical setting the iLA has been applied in a variety of clinical situations, such as severe chest trauma, pneumonia, adult respiratory distress syndrome, and airway obstruction. Furthermore, it has been helpful in the weaning process from mechanical ventilation in a single case. ${ }^{7}$ However, the role of iLA in LTx has not been investigated yet. Here we report on our initial experience with the iLA as a bridge to LTx in patients with end-stage pulmonary failure.

\section{Methods}

Between March 2003 and March 2005, 176 LTx procedures were performed at the Hannover Thoracic Transplant Program, of which
$60 \%$ were HU LTxs for patients who fulfilled the HU criteria postulated by the European Donor Allocation Foundation EuroTransplant.

The iLA was CE certified in Europe in 2003 as an extracorporeal gas exchange device to allow protective mechanical ventilation and as a rescue device in patients with ventilation-refractory lung failure. This study was a prospective observational study approved by the ethics committee of the Hannover Medical School. All patients were sedated and ventilated at maximum levels at the time of the decision for device implantation, and therefore patients' advocates consented to participate in the study.

Twelve of the HU recipients had severe ventilation-refractory hypercapnia and respiratory acidosis and were screened for iLA implantation. After exclusion of all potential contraindications for iLA, which include low cardiac output, cardiogenic shock, and advanced peripheral atherosclerosis, ${ }^{8}$ venoarterial cannulation for device connection in a femorofemoral position was performed. In all patients arterial blood samples were taken for blood gas analysis immediately before iLA implantation. Further arterial blood gas samples were taken 6, 24, and 72 hours and 7 days after iLA implantation. Because of clinical constraints, the available values closest to the previously listed time points were used for the analysis. In addition, systemic arterial blood pressure, peak ventilatory pressure, fraction of inspired oxygen, and positive endexpiratory pressure were prospectively recorded and retrospectively analyzed, and the $\mathrm{PaO}_{2}$ /fraction of inspired oxygen ratio was calculated.

\section{Implantation Technique}

Before iLA implantation, all patients received an intravenous single dose of heparin of 10,000 IU. Implantation of the cannulas was performed under sterile conditions in the intensive care unit. An arteriovenous shunt was instituted by using 2 low-resistance cannulas. First, the left femoral artery was punctured, and a guide wire was introduced (Seldinger's technique). The puncture hole was then dilated to the diameter of the cannula $(15 \mathrm{~F})$ with a dilator kit provided by the manufacturer. The cannula was introduced into the artery and clamped. Next the right femoral vein was also punctured transcutaneously, and a wire was introduced, which guided a $17 \mathrm{~F}$ cannula into the femoral vein. The lung assist device and the short tubing system were completely deaired with normal saline solution by a perfusionist. Finally, the tubes were connected to the cannulas, and the clamps were removed. Immediately, blood flows through the arterial line into the device and returns through the venous cannula. A gas tube that provides the oxygen is connected to the device. A flow probe can be connected to the tubing line to monitor the circulating blood volume through the device. All patients received continuous intravenous heparin administration according to the activated clotting time, which was kept at 160 to 180 seconds and measured in 4-hour intervals. Accidental clotting of the membrane can be detected by continuous iLA blood flow monitoring. However, if this probe is not available, blood gas analyses from the venous line can also indicate malfunction of the iLA. In our patients proper function of the device was tested by using repeated blood gas analyses from the venous line in 8-hour intervals. We tried to keep mean arterial blood pressure greater than $80 \mathrm{~mm} \mathrm{Hg}$ to achieve adequate blood flow through 


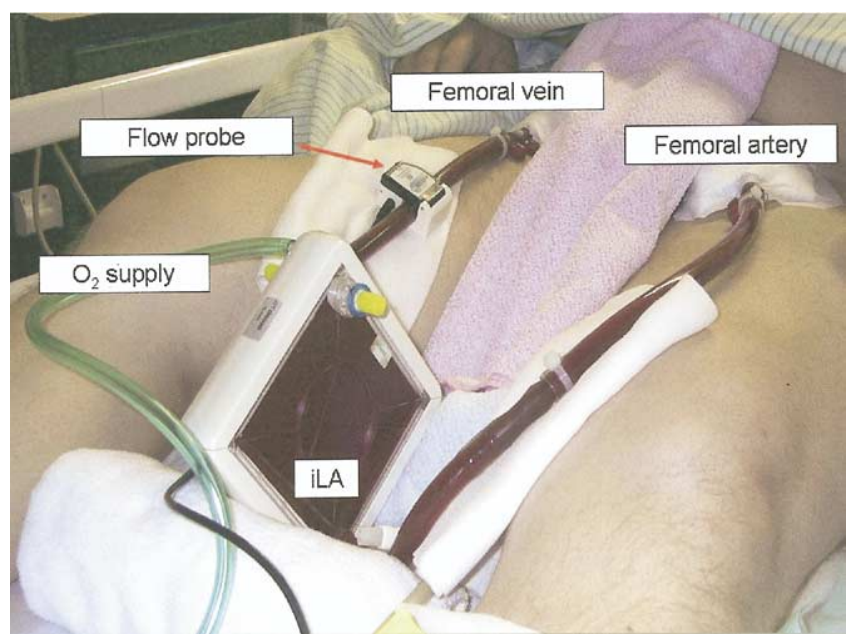

Figure 1. Femoral connection of the interventional lung assist device (iLA) in the clinical setting.

the iLA. If necessary, patients received continuous low-dose norepinephrine administration. Figure 1 depicts the interventional lung assist after femoral arteriovenous insertion. It is noteworthy that the device is placed in a stabile position between the patient's legs for proper function. In all patients the blood supply to the lower extremities was frequently checked by the physician in charge using clinical examination or Doppler ultrasonography.

\section{Statistical Analysis}

Where the assumptions of homogeneity and normality were met, the $t$ test was used. Where these assumptions were not met, the Mann-Whitney $U$ test was used. The SigmaStat version 1.0 (Jandel Scientific, San Rafael, Calif) software package was used for all statistical analyses.

\section{Results}

All patients were mechanically ventilated and sedated. The indication for iLA implantation was ventilation-refractory hypercapnia with accompanying severe respiratory acidosis.
The underlying diseases were bronchiolitis obliterans in 3 patients who were listed for redo LTx, idiopathic pulmonary fibrosis in 4 patients, cystic fibrosis in 2 patients, emphysema in 1 patient, inhalation trauma in 1 patient, and lymphangioleiomyomatosis in another patient. The mean duration of iLA support in the 12 patients was $15 \pm 8$ days (4-32 days). Arterial blood gas analyses before iLA implantation revealed $\mathrm{PaO}_{2}, \mathrm{pH}$, and $\mathrm{PaCO}_{2}$ values of $71 \pm 27 \mathrm{~mm} \mathrm{Hg}$, $7.121 \pm 0.1$, and $128 \pm 42 \mathrm{~mm} \mathrm{Hg}$, respectively. Six hours after iLA implantation, however, $\mathrm{PaO}_{2}, \mathrm{pH}$, and $\mathrm{PaCO}_{2}$ values had changed to $83 \pm 17 \mathrm{~mm} \mathrm{Hg}, 7.344 \pm 0.1(P<.05)$, and $52 \pm 5 \mathrm{~mm} \mathrm{Hg}(P<.05)$, respectively. Table 1 summarizes changes in arterial blood gases and the arterial $\mathrm{pH}$ over time and also changes to the ventilatory regimen. Three patients required replacement of the device for accidental clotting at activated clotting times of less than 150 seconds. In these patients only the membrane required replacement, and the in situ cannulas were left in place. Four patients died of multiorgan failure, 2 before LTx and 2 on days 16 and 30 after LTx. Thus, 10 of the 12 patients were successfully bridged to LTx, and 8 are still alive, resulting in a posttransplantation 1-year survival of $80 \%$. None of the patients showed signs of malperfusion of the lower extremities. Seven of the 12 patients with iLAs had systemic infection or sepsis, as evident by positive blood cultures. Traditionally, such infections would be viewed as contraindications to conventional ECMO in our institution.

\section{Discussion}

We report a novel experience with the pumpless iLA as bridge to LTx in patients with ventilation-refractory severe hypercapnia and respiratory acidosis while awaiting transplantation. These patients require extracorporeal gas exchange and, until now, ECMO was the only available treatment option. In 1991, we reported on the use of ECMO for bridge to redo LTx in patients with severe initial graft failure, thereby addressing the abundance of severe complications with ECMO in lung transplant recipients. ${ }^{9}$ Many LTx programs consider mechanical ventilation or the need

TABLE 1. Changes in blood gases, hemodynamics, and the ventilatory regimen

\begin{tabular}{|c|c|c|c|c|c|}
\hline & \multirow{2}{*}{$\frac{\text { Before iLA }}{\mathrm{BL}(\mathrm{n}=12)}$} & \multicolumn{4}{|c|}{ After iLA implantation } \\
\hline & & $6 \pm 0 h(n=12)$ & $24 \pm 5 h(n=12)$ & $72 \pm 6 h(n=10)$ & $7 \pm 0.5 \mathrm{~d}(\mathrm{n}=7)$ \\
\hline $\mathrm{MAP}(\mathrm{mm} \mathrm{Hg})$ & $72 \pm 8$ & $74 \pm 7$ & $78 \pm 8$ & $77 \pm 6$ & $75 \pm 5$ \\
\hline $\mathrm{PaO}_{2}(\mathrm{~mm} \mathrm{Hg})$ & $71 \pm 27$ & $83 \pm 17$ & $124 \pm 42$ & $113 \pm 28$ & $114 \pm 36$ \\
\hline $\mathrm{PaCO}_{2}(\mathrm{~mm} \mathrm{Hg})$ & $128 \pm 42$ & $52 \pm 5$ & $51 \pm 33$ & $48 \pm 8$ & $46 \pm 5$ \\
\hline $\mathrm{pH}$ & $7.121 \pm 0.1$ & $7.344 \pm 0.1$ & $7.378 \pm 0.2$ & $7.368 \pm 0.1$ & $7.392 \pm 0.1$ \\
\hline $\mathrm{PO}_{2} / \mathrm{FlO}_{2}$ ratio & $135 \pm 33$ & $150 \pm 24$ & $168 \pm 42$ & $145 \pm 24$ & $139 \pm 22$ \\
\hline Peak VP $(\mathrm{mm} \mathrm{Hg})$ & $45 \pm 5$ & $45 \pm 5$ & $32 \pm 3$ & $30 \pm 5$ & $28 \pm 6$ \\
\hline PEEP (mm Hg) & $13 \pm 1$ & $13 \pm 1$ & $6 \pm 1$ & $5 \pm 2$ & $6 \pm 1$ \\
\hline
\end{tabular}

$i L A$, Interventional lung assist device; $B L$, baseline before interventional lung assist device implantation; $M A P$, mean arterial blood pressure; $F 1 O_{2}$, fraction of inspired oxygen; $V P$, ventilatory pressure; PEEP, positive end-expiratory pressure. 
TABLE 2. Technical data of the interventional lung assist NovaLung

\begin{tabular}{ll}
\hline Membrane & Polymethyl pentene diffusion \\
Surface area & $1.3 \mathrm{~m}^{2}$ \\
Blood flow & $0.5-4.5 \mathrm{~L} / \mathrm{min}$ \\
Maximum gas flow & $15 \mathrm{~L} / \mathrm{min}$ \\
Filling volume & $240 \mathrm{~mL}$ \\
Pressure decrease & $11 \mathrm{~mm} \mathrm{Hg}$ at $2.5 \mathrm{~L} / \mathrm{min}$ \\
Pmax & $200 \mathrm{~mm} \mathrm{Hg}$ \\
Coating & Protein matrix + heparin \\
Filling & Connect to normal saline for 3 minutes
\end{tabular}

Designed for pulsatile blood flow. Pmax, Maximum pressure.

for ECMO as a contraindication for LTx because the outcome after LTx under these circumstances has been poor. The widely known side effects of ECMO, such as hemolysis, bleeding complications, severe infection, and renal insufficiency, certainly contribute to this poor outcome. Moreover, ECMO can only be applied reasonably for several days. Beyond that, the number of accompanying complications increases significantly.

The iLA is a low-gradient device designed to operate without the help of an external pump. On the basis of this principle, adequate mean arterial blood pressure is mandatory. This device is attached to the systemic circulation and receives only part of the cardiac output for extracorporeal gas exchange. This allows complete $\mathrm{CO}_{2}$ removal, which can be controlled by varying sweep gas flow. Oxygenation, however, depends on shunt, arterial oxygenation saturation, and other variables. The native lung in this situation also contributes. The limited increase in oxygenation, as seen in the early postimplantation period in our patients, might potentially be life saving in some patients with oxygenation deficiency. However, patients with a primary oxygenation disorder might not necessarily benefit from iLA. ${ }^{7}$ Important technical details of the iLA are depicted in Table 2.

The concept of interventional lung assistance was mentioned by Rashkind and colleagues in $1967 .{ }^{10}$ Various clinical and experimental modifications and studies were performed until the first commercially available pumpless lung assist device, which is the NovaLung, had been developed (Figure 1). In 1999, Zwischenberger and associates ${ }^{11}$ reported on a series of 5 patients who were approved for treatment of severe respiratory failure and $\mathrm{CO}_{2}$ retention to evaluate the feasibility and safety of percutaneous arteriovenous $\mathrm{CO}_{2}$ removal $\left(\mathrm{AVCO}_{2} \mathrm{R}\right)$. In that initial clinical study with a pumpless low-resistance oxygenator (Affinity; Avecor Cardiovascular, Plymouth, Minn), approximately $70 \% \mathrm{CO}_{2}$ removal in adults with severe respiratory failure and $\mathrm{CO}_{2}$ retention was achieved without hemodynamic compromise or instability according to mean arterial blood pressure measurements. This is consistent with our findings with the Novalung. The hemodynamic stability while con- nected to an $\mathrm{AVCO}_{2} \mathrm{R}$ device has also previously been reported in adult sheep by the same group of researchers. ${ }^{12,13}$ In another study by this group, ventilation pressures could be significantly reduced in a sheep model of severe pulmonary injury caused by smoke inhalation after connection of the animal to a low-resistance $\mathrm{AVCO}_{2} \mathrm{R}$ device. ${ }^{14}$ This is also consistent with our findings in this clinical study using the low-resistance iLA.

The Novalung has been applied in approximately 500 cases worldwide, including trauma, lung infection, adult respiratory distress syndrome, airway obstruction, and others, as reported by Matheis. ${ }^{7}$ In the majority of cases reported, the iLA was an adjunct to mechanical ventilation that allowed use of optimized lung-protective ventilation strategies, with the objective of giving the lung time to heal while attempting to minimize ventilation-induced lung injury. Moreover, in single cases the iLA was used without mechanical ventilation in the awake and nonsedated patient. $^{7}$ This is the first report on the application of the iLA as a bridge to LTx. Patients with end-stage lung failure in whom maximal conventional ventilatory support fails are a very high-risk population. Nevertheless, 10 of 12 patients were successfully bridged to LTx, of whom 8 are still alive. The 2 patients who died before LTx died of severe infection. The other 2 patients, who died after LTx, had remote organ failure before transplantation and died of multiorgan failure after LTx. In these cases it is possible that iLA implantation should have been performed at an earlier point in time. On the basis of these promising results, we have changed our approach toward earlier implantation of this lung assist device in mechanically ventilated patients who require advanced ventilatory support. This strategy provides the unique ability to separate ventilation from oxygenation and therefore likely will help to prevent additional ventilationassociated lung injury, which is becoming increasingly recognized as a contributor to remote organ failure. ${ }^{4}$

We acknowledge the following limitations of this study. We decided to assess device function by blood gas analysis on samples taken from the venous outflow cannula. Therefore, we have not measured device flow. Another parameter that would reflect the efficiency and efficacy of the iLA better would be the $\Delta \mathrm{PO}_{2}$ and $\Delta \mathrm{PCO}_{2}$ calculated from the corresponding gas pressures in the arterial inflow and the venous outflow cannulas. We have also not assessed hemodynamic changes in the pulmonary vasculature or the cardiac output, but we underscore that these measures are affected by a variety of other confounding synchronous factors, such as nitric oxide inhalation, prostaglandin nebulization, $\mathrm{PaCO}_{2}$ levels, catecholamine support, ventilatory setup, primary lung disease, and others. Furthermore, the number of patients in this study is small.

In conclusion, our initial experience demonstrates the applicability of the iLA as a bridge to LTx in patients with 
end-stage lung failure. There are unique strategies to this device, such as its pumpless character and its ability to effectively remove $\mathrm{CO}_{2}$. Thereby it normalized the $\mathrm{pH}$ in our patients. The interventional lung assist is our favored treatment for patients with ventilation-refractory lung failure with predominant hypercapnia and respiratory acidosis. Future studies should investigate further some of the theoretic potential advantages of iLA, such as whether the iLA can be used to reduce intracranial pressure by keeping $\mathrm{CO}_{2}$ levels low or to prevent ventilation-induced lung injury and remote organ failure. We are currently examining the role of the iLA in the management of posttransplantation complications, such as severe acute rejection and acute graft failure.

Likely the spectrum of indications for the application of the iLA will increase as we further study the capabilities and limitations of this device.

We acknowledge the invaluable help of Ms Petra Oppelt, who has reviewed statistical data analysis in this study as a professional biostatistician.

\section{References}

1. Trulock EP, Edwards LB, Taylor DO, et al. The Registry of the International Society for Heart and Lung Transplantation: Twentieth Official adult lung and heart-lung transplant report-2003. J Heart Lung Transplant. 2003;22:625-35.

2. Hosenpud JD, Bennett LE, Keck BM, Edwards EB, Novick RJ. Effect of diagnosis on survival benefit of lung transplantation for end-stage lung disease. Lancet. 1998;351:24-7.
3. Smits JM, Mertens BJ, Van Houwelingen HC, Haverich A, Persijn GG, Laufer G. Predictors of lung transplant survival in EuroTransplant. Am J Transplant. 2003;3:1400-6.

4. Imai Y, Parodo J, Kajikawa O, et al. Injurious mechanical ventilation and end-organ epithelial cell apoptosis and organ dysfunction in an experimental model of acute respiratory distress syndrome. JAMA. 2003;289:2104-12.

5. Fischer S, Strueber M, Haverich A. Clinical cardiac and pulmonary transplantation: the Hannover experience. Clin Transpl. 2000;311-6.

6. Fischer S, Strueber M, Haverich A. Current status of clinical lung transplantation: patients, indications, techniques and outcome. Med Klin. 2002;97:137-43.

7. Matheis G. New technologies for respiratory assist. Perfusion. 2003; 18:245-51.

8. Liebold A, Phillip A, Kaiser M, Merk J, Schmid XF, Birnbaum DE. Pumpless extracorporeal lung assist using an arterio-venous shunt. Applications and limitations. Minerva Anestesiol. 2002;68:387-91.

9. Jurmann MJ, Haverich A, Demertzis S, Schaefers HJ, Wagner TO, Borst HG. Extracorporeal membrane oxygenation as a bridge to lung transplantation. Eur J Cardiothorac Surg. 1991;5:94-8.

10. Rashkind WJ, Miller WW, Falcone D, Toft R. Hemodynamic effects of arteriovenous oxygenation with a small-volume artificial extracorporeal lung. J Pediatr. 1967;70:425-9.

11. Zwischenberger JB, Conrad SA, Alpard SK, Grier LR, Bidani A. Percutaneous extracorporeal arteriovenous $\mathrm{CO}_{2}$ removal for severe respiratory failure. Ann Thorac Surg. 1999;68:181-7.

12. Brunston RL Jr, Tao W, Bidani A, Alpard SK, Traber DL, Zwischenberger JB. Prolonged hemodynamic stability during arteriovenous carbon dioxide removal $\left(\mathrm{AVCO}_{2} \mathrm{R}\right)$ for severe respiratory failure. J Thorac Cardiovasc Surg. 1997;114:1107-14.

13. Brunston RL Jr, Tao W, Bidani A, Traber DL, Zwischenberger JB. Organ blood flow during arteriovenous carbon dioxide removal. ASAIO J. 1997;43:M821-4.

14. Tao W, Brunston RL Jr, Bidani A, et al. Significant reduction in minute ventilation and peak inspiratory pressures with arteriovenous carbon dioxide removal during severe respiratory failure. Crit Care Med. 1997;25:689-95. 